\title{
Menstruation Mediated: Monstrous Emergences of Menstruation and Menstruators on YouTube
}

\author{
Lise Ulrik Andreasen
}

\section{Introduction: Menstruation on YouTube}

YouTuber Kristine Sloth's video Tea-time with . . . from 2014 was one of the first videos made by a Danish YouTuber to address menstruation. Since then YouTuber Julia Sofia has been another pioneer in talking about menstruation on YouTube. Menstruation has now become almost an imperative theme for any self-respecting Danish YouTuber. This means that most menstruating YouTubers have at least one video about menstruation and the popularity of the theme has resulted in some of the most popular YouTubers doing commercial collaborations with major menstrual product companies. Videos made by teenage YouTubers for teenage viewers have become increasingly popular in Denmark, where 99\% of all Danish teens between 15 and 18 years use YouTube (Statistics Denmark 2017). Some Danish YouTubers have hundreds of thousands of subscribers and YouTube is now the online platform where most files are shared (Balleys 2017).

Media and youth scholar Claire Balleys observes that YouTube "provides a brand new world for expressing, experimenting with and negotiating adolescence" (Balleys 2017, 227). As menarche and menstruation are central events for many going through adolescence, YouTube also provides a space for re-negotiations and new emergences of menstruation and menstruating subjectivities. The two YouTubers in the center of this chapter, Julia Sofia and Kristine Sloth, are not a part of the global group of feminist activists and scholars who through the last decade have been successfully making menstruation visible in the mainstream (Bobel 2010). When Danish teen YouTubers choose to talk about menstruation, they speak in the confessional, intimate 
style of the teen YouTube genre, where YouTubers take their own life experiences as vantage point for the conversation:

APOLOGIZE (sic) in advance to the delicate souls who cannot handle the honest talk about menstruation. That is the way it is on my channel. Story of being woman. Here is my morning routine! (Kristine Sloth 2015, "My morning routine")

To be honest, menstruation is something that gets to all of us, and instead of just going around whining about what a freaking downer it is - because it is, then we can do somethings to help ourselves and make it all a little easier, so we don't have to worry all of the time. Because in that way, we are winning and not the devil menstruation. Does it make sense? (Julia Sofia 2016, "Beat your Menstruation")

This genre represents new forms of intimacy made possible by the distance of the internet (Andreassen et al. 2017) and this enables the YouTubers to connect with their viewers. As Balleys puts it, "[b]y making themselves the subject and expressing themselves publicly, teenagers are conducting an exercise in social and identity positioning, leveraging intimacy to tell their stories and triggering recognition and identification in their online audience" (Balleys 2017, 227). When watching teen YouTube videos about menstruation, some of the menstrual negotiations stick out from how menstruation has emerged in the past. The move away from more traditional sources of menstrual knowledge, like youth magazines, classrooms (for example, see Ghanoui, this volume, Chapter 67), or the school nurse's office, and into the hands of teens with digital knowledge, means that menstruation is re-negotiated by teen menstruators themselves, which makes new emergences possible.

Where menstruation in traditional, mainstream discourses has been portrayed through narratives of happiness, cleanliness, and control (Kissling 2006; Ussher 2006), some YouTubers now deal with menstruation through affective and, I argue, subversive strategies where humor and disgust intersect. They do this by engaging with what media scholar Maria Parsons refers to as the menstruous-monstrous (2009).

\section{In-Between AND ElSEWHere}

As uterine blood that has left the body is considered in-between and an object of otherness, so is the monster. Throughout time, writers and scholars have explored cultural ideas connecting bodies that bear a "seeping, leaking bleeding womb" (Ussher 2006, 1) to the monstrous (Braidotti 2000; Cohen 1996; Haraway 1992; Kristeva 1982; Parsons 2009; Ussher 2006). Representative of uncontrollable nature, moisture, pain, and weakness, the idea of the womb-bearing subject as monstrous can be seen as pointing out limited and undesirable subject positions for menstruators: positions of 
suppression, shame, and internalized hate toward one's body (Ussher 2006), which can be understood as effects of an archaic patriarchal and sexist culture.

However, considering these new emergences of menstruation on YouTube, I will argue that menstrual connections to the monstrous might work as affirmative and immanent critiques (Butler 2002; Foucault 1997). Exploring relationships of power is central to feminist critique (Butler 2002), and thus an affirmative critique of menstrual norms will aim at identifying and exploring normative breaking points and possible turns toward a promise of a menstrual everyday utopia which offers new, multiple, and inclusive ways and spaces of doing menstruation and being/becoming menstruator. In the words of feminist philosopher Donna Haraway, this utopia could be an undefined place of feminist science fiction and promise, simply called Elsewhere (Haraway 1992).

Through my initial skeptical viewing, I first considered the menstruationthemed YouTube videos as merely another way of capitalizing on adolescent menstruators' fears of losing control over their bodies (Kissling 2006). Some of the videos are most likely exactly that, but through a careful and open reading (Staunæs 2007), which turned my attention toward the complexity and messiness of how menstruation emerges in the videos, they seemed to hold potential for something else.

\section{The Promise of Monsters}

In the horror movie Carrie (1970), a bullied teenager gains special powers when entering menarche (Parsons 2009). Something similar happens in the Canadian horror movie Ginger Snaps (2000), when a teen gets bitten by a werewolf on the night of her menarche. The title character in Buffy the Vampire Slayer (1992) is a high school student with special vampire-slaying powers, who experiences PMS and cramping as a warning when a vampire is around. There are numerous accounts in popular culture and cultural history where the supernatural is connected to menstruation (Parsons 2009; Ussher 2006). While these stories can be read as merely reinforcing stereotypes of menstruators as freaks of nature, I would argue that menstruous-monstrous narratives hold imaginative and emancipatory potential. In a normative and restrictive matrix where menstruators are expected to manage their body through concealment, medicine, and technology, maybe the menstrual monster we meet in tales like these, who is unintelligible and moves across the lines of menstrual norms, can be viewed as a positive figure of transgression. With the words of Henriksen et al., "What kind of critical and imaginative work, does the monster as a guide make (im)possible?" (Henriksen et al. $2017,4)$.

Haraway argues that because transformation happens through difference, the monster can be a promising figure (Haraway 1992). In a similar way monster scholar Jeffrey Jerome Cohen proposes the monster can act as a guide for imaginative thinking to access alternative spaces: 
The monster is difference made flesh, come to dwell among us. In its function as dialectical Other or third-term supplement, the monster is an incorporation of the Outside, the Beyond - of all those loci that are rhetorically placed as distant and distinct but originate Within. Any kind of alterity can be inscribed across (constructed through) the monstrous body, but for the most part monstrous difference tends to be cultural, political, racial, economic, sexual. (Cohen 1996, 7)

The monster as difference is a suitable inhabitant roaming the liminal locus of adolescence, where for womb-bearing subjects, menstruation and the coming of menarche in itself de-centralizes and places the subject in a position of otherness, by shaking it with affects such as pain, shame, alienation, not-knowingness, and discomfort (Oinas 2001; Pendergast 1992; Rembeck 2008; Ussher 2006). The expectation of menarche is the expectation of the crossing of a border-to-come and to menstruate is to become (an)Other.

To follow the monster means looking to process (Haraway 1992) and to let go of, what Butler refers to as proper objects (Butler 1994). Feminist philosopher Rosi Braidotti proposes, "the monster is a process without a stable object. It makes knowledge happen by circulating sometimes as the irrational non-object" (Braidotti 1994, 300). Engaging with the monstrous thus directs my attention toward the moving and affective entanglements through which menstruation is co-constructed on teen YouTube videos. Understanding affects as local, cultural, and relational forces (Ahmed 2004), affect becomes a context through which we can read the monster: "The monster is born only at this metaphoric crossroads, as an embodiment of a certain cultural moment - of a time, a feeling, and a place. The monster's body quite literally incorporates fear, desire, anxiety, and fantasy ... " (Cohen 1996, 4).

With this in mind, I will take the monster by its slimy hand, to look for signs of YouTubers performing what I will refer to as monstrous menstruation and menstrual trouble. Inspired by Butler (1990), I see trouble as small agential cracks in normative scripts of how to do menstruation. Social psychologist Dorthe Staunæs gives a helpful account of trouble as "an antagonistic force, which goes against the force, which is currently dominating. It is a challenging force up against the force, which is currently working towards making something the norm. Trouble is the tremble and the tension, which worries, threats or promise to subvert or destroy already sediment systems" (Staunæs 2007,263 ). In this case, menstrual trouble can be read as resistance toward narrow menstrual norms.

\section{Multiple Agents}

The monster is embodiment and difference made flesh (Cohen 1996) and when navigating the field of menstruation, the presence of materiality is insistent, in the form of blood, bodies, and menstrual products. This materiality, together with affective intensities and the technological context of YouTube, means that, in addition to menstruating subjects, there are endless 
and multiple agents in play. This calls for an analytical perspective able to capture process, mess, and complication.

Thinking menstruation as situated in culture, time, and space (Hasson 2016; Oinas 2001) and co-produced by multiple agents (Barad 2003) resonates with findings in my own empirical material (Andreasen, forthcoming), where young menstruators experience their menstruating bodies as not being separate from discourse (Oinas 2001). It enables me to engage with empirical material in a way that will better understand complexity by conceptualizing emergences of menstruation as the moving sum of an entangled and messy bundle. This mess gives meaning to what we know as menstruation, or as feminist philosopher Karen Barad more accurately explains it, "It is through specific agential intra-actions that the boundaries and properties of the "components' of phenomena become determinate and that particular embodied concepts become meaningful" (Barad 2003, 16).

Thinking along the lines of Barad's post-humanist re-development of feminist philosopher Judith Butler's theory of performativity (Butler 1990), I can move beyond thinking menstruation, bodies, and subjectivity as either-or, but as always already all (Barad 2003). By doing a strategic de-centering of the menstruating subject, I attempt to do an inclusive move, which also invites us to problematize and think beyond rigid categories. Menstruation is not purely subjective or objective, biological or social, natural or cultural, but is co-produced in encounters of discourse, affect, matter, technology, space, and time. The menstruating body is situated, and with its flow of blood and its cramping uterus, it carries agency in itself. Thus, I understand relational as the always already moving connected processes and intra-actions that entangle, co-construct, and materialize menstruation, menstruating bodies, and menstruating subjects.

\section{Becoming and Emerging on YouTube}

To get a better understanding of how menstruation and menstruating subjects emerge and become (Kember and Zylinska 2012) through monstrous performances in this specific context of YouTube, I look to media scholars Sarah Kember and Joanna Zylinska, who suggest a movement away from the exploration of media as an object, and instead encourage focusing on mediation, "a key trope for understanding and articulating our being in and becoming with the technological world, our emergence and ways of intra-acting with it as well as the acts and processes of temporarily stabilizing the world into media, agents, relations, and networks" (Kember and Zylinska 2012, $\mathrm{xv})$. The menstruating subject is thus not separate from the digital space of YouTube, but exists within and with it. In this sense, here menstruation and menstruating subjects come into being with YouTube and the dichotomy of real and virtual life is rendered useless.

Following Kember and Zylinska I use the Deleuzian terminology of becoming and emerging to reflect my focus on the relationality and process 
that is menstruation. I use the terms broadly, to also cover how the phenomenon of menstruation is continuously re-constructed as part of the process that points out lines of flight for possible menstruating subjectivities. It is worth noticing that becoming can only be a move toward otherness, since the norm already "is." This means becoming can only be a move away from normative positions (Parsons 2009). Menstruation can be seen as an impetus for such a movement away from white hetero-cis-gender hegemony (which already "is") and toward otherness. As Parsons writes, "Menarche and menstruation are the initiators of the line of flight for "becoming" (Parsons 2009, 38), hence becoming-women. The terms of becoming and emergence are meant to serve as affirmative images of menstruation and subjectivities, as always moving, always in the making and as always Other.

\section{Cuts}

YouTube videos are also always moving, and when cutting and drawing lines in images, sound, and theory, which grabs and freezes images, the researcher acts as a co-constructing agent. Writing about moving audio-visual images, one is doomed to miss important dimensions. My cuts in the material are marked by ( . . . ), to further transparency by indicating missing parts of the videos. The YouTubers also make cuts that matter (Barad 2007). Together with fast voices, bodies, music, spaces, clothes, make up, camera angles, zooms, and text applied in editing programs, multiple agents are involved in the mediation of menstruation and all of this matters for how menstruation emerge. In the case of the YouTubers' editing, a style of extensive and abrupt cutting produces high-energy videos, where menstruation emerges through intensity. ${ }^{1}$ The way the videos are produced and edited thus decides how and what we know about menstruation.

\section{The Smoothie Challenge}

Hey friends, and welcome to this video! Today we are going to do a mega nice video, because this video is made in collaboration with Libreeeeeesse! ${ }^{2}$

Julia Sofia's hands appear in the frame, each holding and shaking a pink package of menstruation pads. Julia Sofia's younger sister Ida is in the video as well and she explains that they are going to do a smoothie challenge.

Julia Sofia and Ida are both white, middle-class teenagers. They are well dressed in casual good quality clothes, accessorized with trendy and relatively expensive jewelry. Their hair is healthy-looking and their makeup follows certain codes for Danish middle-class everyday makeup, dictating "not too much."

Doing different kinds of challenges is a well-known and popular feature within the YouTube genre. Often it involves the YouTuber being challenged to consume something considered disgusting. Julia Sofia explains that she and 
her sister will take turns answering questions about menstruation, and choose red ingredients for each other's smoothies. At the end of the quiz, they are going to taste the smoothies and test how well the menstruation pads can absorb the red liquids.

$(\ldots)$

The frame zooms out, and we see Julia Sofia and Ida sitting on a white couch behind a coffee table, where there is a spread of red foods and liquids, which Julia Sofia identifies as follows:

There is some red soda, and some cranberry juice. Then there is some pomegranate seeds, and some pickled beetroot, some raspberries, a bit of ketchup. We have some raspberry marmalade and finally we have some Siracha, which is stinking up the whole room.

Julia Sofia then explains how they are going to blend it all together and Ida adds, "You get a sense of the red theme right? Menstruaation!!!", while she does a V-sign with her hand and both sisters laugh. On the wall behind the couch are two posters with the inspirational quotes, "Your body loves you, love it back" and "Be your own kind of beautiful."

\section{Our Little Juices}

As the video moves along, each girl answers questions about menstruation. Wrong answers are penalized by a sister choosing a red ingredient for the other to put in their blenders.

When it comes to the moment of blending, an out of place event occurs. Julia Sofia's sister Ida blends her ingredients to a bright red liquid, while anxiously uttering, "I am seriously scared." She then screws the lid of the bottle and both sisters smell the liquid with disgust: "Ooooh it smells baaad!" Laughing while making a face of repugnance, Julia Sofia shakes her blender bottle while stating, "I'm scared to shake this, because it contains soda." Then she places the container on the blender and blends the ingredients to a soft red liquid. After blending, Julia Sofia, now displaying a skeptical expression, screws the lid off and the red liquid squirts out of the bottle, as Julia Sofia laughingly screams, "Oh no Ida!".

The video then CUTS to slow-motion, and replays the incident with distorted sound. The container that was to serve as a border between the red matter and the outside has failed. As the red liquid moves beyond the borders of the civilizing bottle, it becomes out of place. The red liquid escapes from the bottle, accompanied by Julia Sofia's slowed and distorted monster-like face and voice underlining the disorderliness of menstruation. The slow temporality of the clip enables us to see the $\mathrm{CO}_{2}$ induced force behind the mixed red ingredients, as the liquid squirts out of the bottle. The guttural and slow "ooooooooh nooooooooo . . ." of Julia Sofia, is not the sound of a human, but the deep roar of a monster. Julia Sofia with her slow moving lips and 
distorted face with mediation becomes a monstrous menstruator, with squirting liquids out of place. By the agency of technology, time is done differently, which alters affectivities, matter, space, sound, and thus the emergence of menstruation.

The monstrous performance continues when the sisters drink the red smoothies resembling menstrual blood. The smoothie makes Ida drool, and she holds her hands under her chin, to catch the escaping fluid, and we again see a display of disgust entangled with laughter. In this way menstruation emerges through connections with affective displays of disgust (Oooob it smells bad), fear (I am scared), and laughter. Except for their reaction to the nontraditional combination of ingredients, the sisters' performance can be read as connected to a long tradition of positioning the menstruating body in a place of fear and disgust. However, as Julia Sofia and Ida each take a sip of their smoothies, and drink what mimics menstrual blood, cracks in the foundation of normative menstrual behavior appear. As the sisters drink, they perform outside proper performances of middle-class femininity, by breaking norms for how to engage with menstrual blood (Kristeva 1982; Ussher 2006).

The two sisters move on to the final part of the video, where they test how well the menstrual pads will absorb the red liquid. As each girl tears open a pink and white wrapper, Julia Sofia says, "This is my favorite part," to which Ida replies, "Yes, just the sound." CUT. "So what we are testing now is whether these pads can absorb our little juices." As Ida spreads a teaspoon of red liquid across the pad, which has been stuck to the coffee table, Julia Sofia exclaims, "Yes thank you, Yes thank you!" Her sister replies, "Oh yes!" Both sisters laugh, and Julia Sofia says, "OK, that's actually a little more intense than I expected it to be." CUT.

This section is edited with cross clips from Julia Sofia's smart phone, which she uses for close-ups of the pads. The close-ups allow the viewer to see how lumpy and foamy the liquids are. Ida says, "Julia, there is a little too much foam on yours." She continues, "Well, you cannot get around there being some bits of pomegranate in this," while she swings the pad from side to side, which makes Julia burst out into a high pitch laugh. CUT. The video concludes with Julia Sofia exclaiming: "We just did this!" Both sisters are holding the pads with the smoothie surface facing the camera. This time they are holding it with two fingers, as if using a pair of tweezers.

When Julia Sofia and Ida construct an assemblage of affects, objects, sounds, and words which makes menstruation emerge in an entanglement of materiality and affects like disgust, fear, and humor and as menstruous-monstrous (Parsons 2009), it could lead to the conclusion that they are reinforcing the very stigma they aim to break. Nevertheless, I would argue that the dichotomous division of stigma or not-stigma is too simplistic here. Instead, I want to propose the idea that the connection to disgust in the case of Julia Sofia's smoothie challenge is what enables menstruation to emerge at all. The YouTubers play with disgust can actually be seen as an act of subversion and a 
way of gaining power over what menstruation can be. The fact that the red, lumpy, and foaming liquid is in the very center of the video, and that it is not only produced, but also drunk and then applied to menstruation pads, can be considered menstrual trouble. It stands in contrast to traditional mediated emergences of menstrual blood as a clear blue liquid. When the sisters drink the lumpy red liquid, which they connect to their own menstrual liquids by naming it "our little juices," they consume what is considered unclean, abject, and out of place matter (Kristeva 1982; Ussher 2006) and what Julia Sofia herself in another video refers to as "the devil menstruation." By doing this, they make menstrual trouble, which according to Julia Sofia feels "a little intense"an intensity catalyzed by the performance of a transgressive and subversive act.

\section{My Morning Routine}

YouTuber Kristine Sloth is, like Julia Sofia, a young, white, middle-class cis-woman. Her video My Morning Routine starts with soft music, and we hear the sarcastically excited voice-over of Kristine as we see her rolling around her bed. Kristine is wearing a sweater and no trousers, her hair is greasy and messy and she is not wearing makeup. Her room is also messy, her laptop is thrown on her bed and things are scattered all over. CUT. We see Kristine sitting on the toilet, where she picks up a packet of menstrual pads. It is empty. She throws it on the floor, and then picks another one up as the voice-over continues.

Yes, I am looking for pads in this scene, because I have my menstruation these days. And yes, it's the worst thing I can think of. You all have been real lucky for this morning routine, because you have won me on all the best times of the month, but eeeh, I always use night pads because I bleed worse than a hippo, so yes, these are the biggest diapers on the market, for the woman with menstruation, these are from Always, they are really fucking great, because they are also scented by the way, yes but I'm really fucking tired, yes I'm really pretty in this shot.

We see Kristine yawning, still sitting on the toilet. CUT. Kristine is now sitting by her computer, looking at her phone, when she opens her mouth widely and bends over slowly, as we hear the voice-over: "Right here I'm complaining about my stomach cramps, because I have my menstruation as I told you, and I'm drinking a sip of coffee from yesterday." CUT. We see Kristine go back to bed, where she takes her laptop and starts watching the screen.

I'm just lying here, with my delicious double-chin enjoying life. I would just like to say, and defend all other people who cannot be bothered going to the fitness center and eat a lot of healthy foods every morning, that this is completely normal and that I also do it, so I'm really sympathizing with you, because I 
really don't have the energy to do anything, especially not when I'm menstruating, but yes good night again!

Kristine falls backwards into her bed and closes her eyes. CUT. Kristine appears again, this time talking directly into the camera, about her motives for doing her morning routine in what she describes as a "realistic" style, as opposed to the perfect morning routines she has seen others post on YouTube.

\section{Making Menstrual Trouble}

The menstruating body might experience anger and pain, it might be tired, and it might be bloated and can in itself be considered trouble. As sociologist Elina Oinas puts it, the woman's body is a trouble-making body (Oinas 2001, 58). In this sense, everything we see in Kristine's video is trouble. Kristine appears unclean and the fact that she shows herself sitting on the toilet, while menstruating, troubles normative performances of femininity and menstruating. Through humorous realism, Kristine uses this messy and monstrous performance to propose a way to do menstruator differently. Her sarcastic, energetic, and fresh-sounding voice in the start stands in contrast to her tired looking body, which ignites humor. All the way through the video, she is performing what I would call the monstrous menstruating clown.

By talking about how heavy her flow is, and comparing herself to a very large animal (I bleed worse than a hippo), Kristine not only breaks with menstrual norms of concealment, but also positions herself as non-human and Other. A hippo, monstrous by its mere size (Petersen 2017), places her within the realm of nature, which is beyond control. I would argue that what Kristine is doing, when she performs troublesome monstrous menstruator, can be read as a critique of neo-liberal body ideals, where the individual is responsible for having, building, and keeping a body which appears and functions in accordance with contemporary ideals of strength, thinness, and ability (Eriksen 2017; Fritsch 2015).

Oinas points out that

( ... ) the Nordic girl is marked by paradoxical opportunities and pressures that require both individual strength and social relationality in ways that should be carefully scrutinized rather than sweepingly celebrated. Contemporary girls and young women are expected to embody the autonomous and neo-liberal subject ideal. (Oinas 2017, 179)

Kristine herself refers to the pressure of eating healthy and going to the gym, and she directly protests against this by going back to bed after having her day-old coffee, while her body is kicking back (Barad 2007) in flows of blood and waves of cramps. As feminist scholar Sarah Ahmed would put it, Kristine opposes the "duty of being happy" (Ahmed 2010, 7), by how she does menstruator differently. 
As mentioned above, Parsons suggests a reading of the monster as a promising and transgressive figure, by arguing that . . . the 'leaky' body or its, so-called menstruous-monstrosity is potentially positive, multiple and transgressive and that the 'real' horror in these texts instead resides within the 'Frankensteinian' agencies of family, state, and religion, and in the methods they employ to both create and destroy the 'monster' (Parsons 2009, 192).

So the real horror might lie within contemporary neo-liberal ideals, where menstruators are expected to do anything bleeding and Kristine's negotiation of menstruation through performing monstrous menstruator, can be read as an immanent critique, which points beyond the edges of normative ideas of menstruation.

Kristine's critique takes form through performing a constant menstruating monster, where Julia Sofia performs a happy and clean menstruator, which only turns monstrous at times. However, what is important to notice about both videos is the constant vibrations of humor, which makes doing menstruation differently possible. Both YouTubers take an already established truth of menstruation as disgusting and do something different with it. They work with humor as an affective strategy of subversion. The impetuses for laughter are the affective intensities of the forbidden, the disgusting, and the scary: the monstrous. When the disgusting and scary monster meets humor, it resembles a clown, and the menstruating clown can touch upon the untouchable and become the matter of intense fun. In this way, the monster might awaken through disgust and fear, but it is legitimized through humor. This affective entanglement of fun, fear, and disgust thus becomes the chisel that makes cracks and carves out spaces for menstruation to emerge differently.

\section{Imaginative Re-emergences of Menstruation}

Can the troubling menstrual praxis of the YouTubers be seen as imaginative? And can the videos offer a glimpse of an open-ended menstrual utopia? Perhaps a feminist menstrual sci-fi Elsewhere?

Braidotti argues that "[w]e need to learn to think of the anomalous, the monstrously different not as a sign of pejoration but as the unfolding of virtual possibilities that point to positive alternatives for us all" (Braidotti 2000, 172). If we follow this idea, then the monstrous emergences of menstruation, offered by the young menstruating YouTubers, might point to such positive alternatives or merely some alternatives for "some." Some, because there is an important problem, which needs to be addressed and thought about further.

Both Julia Sofia and Kristine Sloth embody the normative ideals that they are also disturbing and they cannot be seen as representative for all menstruators. From their positions of privilege, they can afford to do menstruation differently without experiencing serious sanctions. The same videos made by less privileged menstruators would result in different outcomes. Menstruation is not a fixed or universal phenomenon and it is important to notice the context 
in which menstruation is situated. Menstruation is local and multiple (Hasson 2016). Menstruation is embodied, it is gendered, it is classed, it is racialized, it is geo-political (Oinas 2017) and thus emerges in various forms and shapes, dependent on the various entanglements through which it becomes intelligible. Menstruation in the context of these Danish white middle-class YouTubers is thus not to be taken as a universal account of a socio-material phenomenon, but as a reading of a localized and situated praxis. It is a praxis that might hold emancipatory potential for some.

The entanglement of whiteness, middle-class, able bodies, technology, and affectivity here act together and allow menstruation to be visible. Through humor, at times generated by editing and use of voice-over, the menstruous monster becomes laughable and maybe even desirable. This carves out a space for the menstrual monster to stay with us and to act as a transgressive figure, which points its monstrous finger toward Elsewhere, a way of doing menstruation differently. By embracing the monstrous, like Kristine Sloth and Julia Sofia do, I read their videos as imaginative work through which they make room for re-negotiations and make different emergences of menstruation possible. No matter possible ulterior motivations like commercial earnings, I will argue that these new openings can be seen as affirmative and as imaginative possibilities. As Haraway puts it, "It's not a happy ending we need, but a non-ending" (Haraway 1992, 110).

\section{Notes}

1. To get a fuller experience, I highly recommend watching the videos in question, in relation to reading this chapter. Links for the videos are provided in the list of references.

2. Libresse is internationally known as Bodyform.

\section{REFERENCES}

Andreasen, Lise Ulrik. forthcoming. Menstruating Subjects and Everyday Life. PhD thesis.

Andreassen, Rikke, M. N. Petersen, K. Harrison, and T. Raun, eds. 2017. Mediated Intimacies: Connectivities, Relationalities and Proximities. London: Routledge.

Ahmed, Sarah. 2004. The Cultural Politics of Emotions. Edinburg: Edinburg University Press.

- 2010. The Promise of Happiness. Durham: Duke University Press.

Balleys, Claire. 2017. “Teen Boys on YouTube: Representations of Gender and Intimacy." In Mediated Intimacies: Connectivities, Relationalities and Proximities, edited by Rikke Andreassen, Michael Nebeling Petersen, Katherine Harrison, \& Tobias Raun. London: Routledge.

Barad, Karen. 2003. "Posthumanist Performativity: Toward an Understanding of How Matter Comes to Matter." Signs 28, no. 3 (Spring): 801-31.

- 2007. Meeting the Universe Halfway: Quantum Physics and the Entanglement of Matter and Meaning. Durham: Duke University Press. 
Bobel, Chris. 2010. New Blood: Third-Wave Feminism and the Politics of Menstruation. New Brunswick: Rutgers University Press.

Braidotti, Rosi. 1994. Nomadic Subjects: Embodiment and Sexual Difference in Contemporary Feminist Theory. New York: Columbia Press.

-. 2000. "Teratologies." In Deleuze and Feminist Theory, edited by Ian Buchanon and Claire Colebrook. Edinburgh: Edinburgh University Press.

Butler, Judith. 1990. Gender Trouble: Feminism and the Subversion of Identity. New York: Routledge.

- 1994. "Against Proper Objects." Differences: A Journal of Feminist Cultural Studies $6(2-3)$ : 1-26.

- 2002. "What Is Critique? An Essay on Foucault's Virtue." In The Political: Readings in Continental Philosophy, edited by David Ingram. London: Basil Blackwell.

Cohen, Jeffrey Jerome. 1996. "Monster Culture (Seven Theses)." In Monster Theory: Reading Culture, edited by Jeffrey Jerome Cohen. Minneapolis: University of Minnesota Press.

Eriksen, Camilla Bruun. 2017. “It's Not Over Until the Fat Lady Loses Weight - Det er ikke slut, før den fede dame taber sig." En form - og normkritik af tv-programmet Min krop til skræk og advarsel. I: Tidsskrift for Kjønnsforskning. Årgang 41 (2): 106-23.

Foucault, Michel. 1997. "What Is Critique?" In The Politics of Truth, edited by Sylvère Lotringer and Lysa Hochroth. Translated into English by Lysa Hochroth. New York: Semiotext(e).

Fritsch, Kelly. 2015. "Desiring Disability Differently: Neoliberalism, Heterotopic Imagination and Intracorporeal Reconfigurations." Foucault Studies 1 (19): 43-66.

Haraway, Donna. 1992. "The Promise of Monsters: A Regenerative Politics for in/ Appropriated Others." In Cultural Studies, edited by Lawrence Grossberg, Cary Nelson, and Paula A. Treichler. New York: Routledge.

Hasson, Katie Ann. 2016. "Not a Real Period: Social and Material Constructions of Menstruation." Gender and Society 30 (6): 958-83.

Henriksen, L., M. Bülow, and E. Kvistad. 2017. "Monstrous Encounters: Feminist Theory and the Monstrous." Kvinder, Køn \& Forskning 26 (2-3). https://doi. org/10.7146/kkf.v26i2-3.100801.

Kember, Sarah, and Joanna Zylinska. 2012. Life After New Media: Mediation as a Vital Process. Cambridge: MIT Press.

Kissling, Elizabeth Arveda. 2006. Capitalizing on the Curse: The Business of Menstruation. Boulder, CO: Lynne Rienner Publishers.

Kristeva, Julie. 1982. Powers of Horror: An Essay of Abjection. New York: Columbia University Press.

Oinas, Elina. 2001. Making Sense of the Teenage Body: Sociological Perspectives on Girls, Changing Bodies and Knowledge. Åbo: Åbo Akademi University Press.

- 2017. "The Girl and the Feminist State? Subjectification Projects in the Nordic Welfare State." In Nordic Girlhoods: New Perspectives and Outlooks, edited by Bodil Forsmark, Heta Mulari, and Myry Voipio Formark. London: Palgrave Macmillan.

Parsons, Maria. 2009. The Menstruous-Monstrous: Female Blood in Horror. Doctoral thesis, School of English, University of Dublin, Trinity College. Accessed date November 12, 2017, Parsons TCD THESIS 9484 The Menstruous Monstrous.pdf. 
Pendergast, Shirley. 1992. This Is the Time to Grow Up: Girls Experiences of Menstruation in School. London: The Family Planing Association.

Petersen, Daniel Otto Jack. 2017. "At the Mountains of Monstrosity: Reading Ontology in a Fjord." Women, Gender and Research 2: 3-17.

Rembeck, Gun. 2008. The Winding Road to Womanhood: Adolescents' Attitudes Towards Menstruation, Womanhood and Sexual Health-Observational and Interventional Studies. Gothenburg, Sweden: University of Gothenburg, Sahlgrenska Academy.

Statistics Denmark. 2017. “It-Anvendelse I Befolkningen.” Accessed April 20, 2018. https://www.dst.dk/Site/Dst/Udgivelser/nyt/GetPdf.aspx?cid=24235.

Staunæs, Dorthe. 2007. "Subversive analysestrategier - eller governmentality med kjole, fjerboa og Sari." Magtballader, edited by Jette Kofoed and Dorthe Staunæs. Copenhagen: Danmarks pædagogiske Universitetsforlag.

Ussher, Jane Mary. 2006. Managing the Monstrous Feminine: Regulating the Reproductive Body. London and New York: Routledge.

\section{YouTube Videos (Authors English Translations)}

Sloth, Kristine. 2014. Tetid med Kristine \#1! (Tea-Time with Kristine \#1!). Accessed August 5, 2017. https://www.youtube.com/watch?v=CoS0len51X0.

- 2015. Min morgenrutine! (My Morning Routine!). Accessed August 5, 2017. https://www.youtube.com/watch?v=jaifDrQ7H80.

Sofia, Julia. 2016. $<3$ Beat din menstruation // Libresse $<3$ (<3 Beat Your Menstruation // Libresse $<3$ ). Accessed August 5, 2017. https://www.youtube.com/ watch?v=HQUwbxZEpec.

2017. THE SMOOTHIE CHALLENGE I Julia Sofia<3. Accessed August 5, 2017. https://www.youtube.com/watch?v=8_r2jrPp4bg.

Open Access This chapter is licensed under the terms of the Creative Commons Attribution 4.0 International License (http://creativecommons.org/licenses/ by $/ 4.0 /$ ), which permits use, sharing, adaptation, distribution and reproduction in any medium or format, as long as you give appropriate credit to the original author(s) and the source, provide a link to the Creative Commons license and indicate if changes were made.

The images or other third party material in this chapter are included in the chapter's Creative Commons license, unless indicated otherwise in a credit line to the material. If material is not included in the chapter's Creative Commons license and your intended use is not permitted by statutory regulation or exceeds the permitted use, you will need to obtain permission directly from the copyright holder.

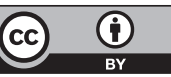

